\title{
Modeling the deformation of faulted volcano- sedimentary sequences associated to groundwater withdrawal in the Querétaro Valley, Mexico
}

\author{
G.H. Ochoa-González $^{\text {a }}$, P. Teatini ${ }^{\text {b }}$, D. Carreón-Freyre ${ }^{\text {c }}$, and G. Gambolati ${ }^{\text {b }}$ \\ ${ }^{a}$ Western Institute of Technology and Higher Education (ITESO), Jalisco, Mexico \\ Email: gilochoa@iteso.mx \\ ${ }^{b}$ Dept. of Civil, Environmental and Architectural Engineering, University of Padova, Italy \\ ${ }^{c}$ Centro de Geociencias, National Autonomous University of Mexico, Queretaro, Mexico
}

\begin{abstract}
The City of Querétaro is located on a graben structure that formed a continental basin filled since the Oligocene time with volcanic and sedimentary materials. In the $\mathrm{N}-\mathrm{W}$ direction two major normal faults are dipping to the West and the thicknesses of the filling materials vary many tens of meters in close distances. The filling materials include lacustrine and alluvial sediments, pyroclastic deposits, and interbedded fractured basalts. Hence, important differences of hydraulic and mechanical properties characterize the various units.

Groundwater was been strongly withdrawn over the last three decades in the study area, with a level decline exceeding than $100 \mathrm{~m}$ in some areas. Because of the high variability of the geological deposits, a space variable decrease of the piezometric levels, and consequently of the effective stress increase, has been observed. Piezometric variations are also due to faults that strongly impact on groundwater flow dynamics. The variable distribution of the effective stress increase has caused large differential subsidence causing ground fracturing that has damaged the urban infrastructures of the City of Querétaro.
\end{abstract}

The geological heterogeneities of the subsoil were integrated into a flow and geomechanical model to predict the deformation caused by fluid withdrawal. Initially the hydrodynamics of the pumped aquifer system was simulated by a 3-D groundwater flow model and then the subsidence was computed with the aid of a 3-D poro-mechanical model with the pore pressure field specified as an external distributed source of strength within the porous medium. The model is calibrated using observed groundwater and land settlement records, with the generated three-dimensional stress field that is compared with the distribution of the major fractures detected in the city.

The aim of this work is to predict the differential deformation of the faulted volcano-sedimentary sequences. The simulation is carried out by an advanced three-dimensional finite-element flowdynamic-geomechanical code. The conceptual model was accurately defined using the correlation of geological logs of extraction wells, field mapping of faults, fractures, and the integration of major structures reported in previous geophysical works. The stratigraphic sequences were simplified with seven mayor hydrogeological units with specific mechanical properties, hydraulic conductivity, and storage capacity. The 30 years records of piezometric level were used to simulate groundwater depletion and the resulting land subsidence.

The results of the geomechanical simulations show that the areas where large differential subsidence developed correspond to the portions of the city where earth fissuring have been observed. The spatial relationship between major withdrawals and the largest simulated subsidence is assessed.

Keywords: Groundwater withdrawals, land subsidence, earth fissuring, modeling, Querétaro (Mexico) 


\section{INTRODUCTION}

Climate changes and, in particular, the decrease in precipitation and increase in temperature, are a very severe problem in desert and semi-desert populated environments, and even more when they are associated with a rapid urban development. This is a typical situation of several cities in the Transmexican Volcanic Belt (Karmalkar et al., 2011), such as Querétaro, Morelia, Celaya, and the most famous case of Mexico City. In this portion of the central Mexico, the groundwater extraction from local aquifers is the primary source of water supply and contributes more than $70 \%$ to the water needs of more than 100 million inhabitants (INEGI, 2011). Overdraft of groundwater resources and, secondarily, the reduction of the natural recharge, have led to a dramatic piezometric decline up to $100 \mathrm{~m}$ in some sites. The consequent consolidation of the sedimentary/volcanic basins resulted in land subsidence with rates of the order of $10 \mathrm{~cm} / \mathrm{yr}$ associated with earth fracturing (Figure 1) (e.g., Pacheco et al., 2006; López-Quiroz et al., 2009; Carreón-Freyre, 2010). In Querétaro as well, the main concern is overexploitation of aquifers that, since the fifties, have provided water to the inhabitants of this Valley and are alarmingly experiencing large piezometric decline from a few meters to about $120 \mathrm{~m}$. Withdrawal has been recently estimated at 110 million $\mathrm{m}^{3} / \mathrm{yr}$ while the total recharge is around 70 million $\mathrm{m}^{3} / \mathrm{yr}$. The valley is composed by highly heterogeneous sand-and-silt sediments with intercalated pyroclastic layers. Failure of the sequence is caused by a differential compaction of the sedimentary deposits and the presence of a pre-existing buried fault scarp (Carreón-Freyre et al., 2005a).

The complexity of the geological system, the piezometric evolution due to groundwater pumping, and the related land subsidence are addressed in this study with the aid of advanced three-dimensional (3-D) finiteelement (FE) flow and geomechanical models. The occurrence is reconstructed since 1970. The model is calibrated using observed groundwater and land settlement records with the three-dimensional stress accumulation compared with the distribution of the major fractures mapped in the city.

\section{QUERÉTARO VALLEY}

The study area is located in the southern part of the City of Queretaro, on a graben structure formed by orthogonal normal faults with approximate trending N-S and E-W within the regional geological unit named Transmexican Volcanic Belt (TMVB) (Alaniz-Alvarez et al. 2001). The N-S trending west-dipping Central fault is the eastern limit of the regional Queretaro graben (Figure 2). Other major faulting family (trending NE-SW) produced a nearly orthogonal pattern with the N-S system that has resulted in a mosaic formed by horsts, grabens, and half-grabens (Xu et al. 2011) with varying vertical displacements, in some areas up to $400 \mathrm{~m}$. Both fault systems have been active at least since the Miocene (Alaniz-Alvarez et al. 2001and controlled the deposition of sediments and volcanic rocks.

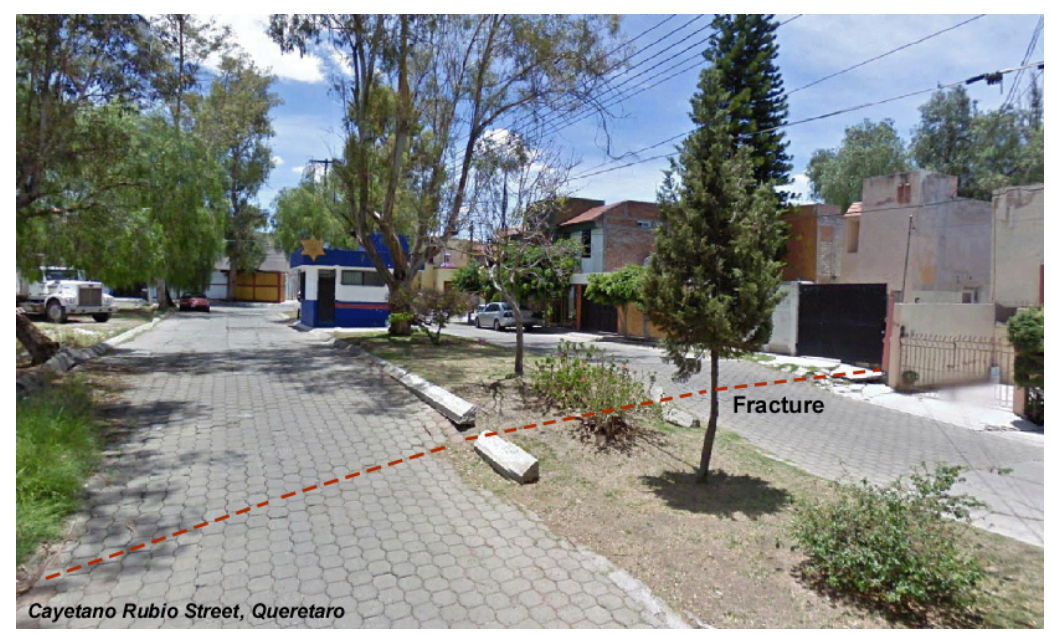

Figure 1. Photo of Querétaro, Cayetano Rubio Street, showing the effect of differential land subsidence due to groundwater withdrawals. The large displacement gradients are responsible for earth fissuring producing significant economic losses and increasing the safety issues in the urban area. 


\subsection{Hydrogeological Setting}

The sedimentary-volcanic basin of the Querétaro Valley is made from seven major geologic units (Figure 3). Some of them are mainly porous formations and other mainly fractured units. Porous deposits are thought to be the more compressible than fractured rocks, and therefore characterized by a larger capability to store water.

The units are listed in the following order from top to bottom: 1) Q clay: Quaternary clays: lacustrine, surficial and thin deposits with low permeability; 2) Tp Ar-Cg: sediments and volcanic rocks, the first main porous unit; 3) Tmt AB: Andesitic and Basaltic fractured unit; 4)Tom Py Lac: pyroclastic and lacustrine deposits forming the second main porous unit; 5) Tmm

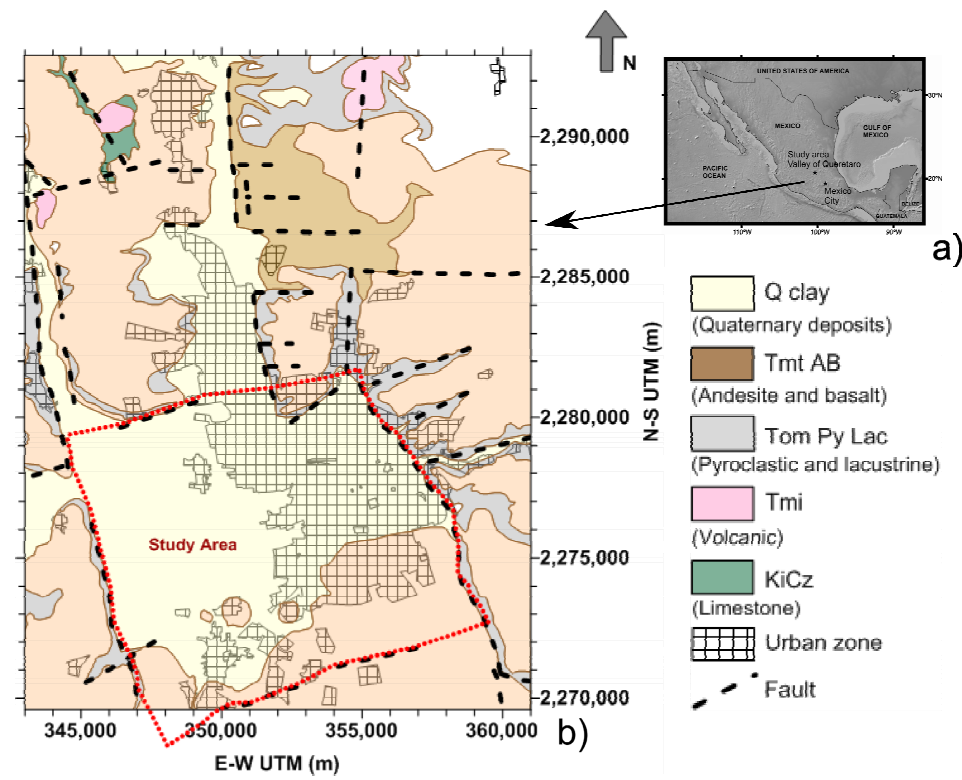

Figure 2. Location of the study site (a) and geological map of the Querétaro valley (b). The simulated area is highlighted by a dotted red line

AB: older Andesitic and Basaltic fractured unit underlying TomPyLac; 6) To AB: another Andesitic and Basaltic fractured unit, adjacent to the TmmAB; it is characterized by a different degree of fracturing relative to Tmm AB, and hence has different hydrogeologic properties; 7) Base: even if probably other porous/fractured materials exist below To AB (Carreon-Freyre et al., 2005b), we assume that the base unit confines the compressible sequences from which groundwater is withdrawn; this unit was simulated in the model as a low permeability and rigid material.

\subsection{Groundwater Resources Withdrawn and Land Deformation}

Figure 4 shows the drawdown in some wells in Queretaro from 1970 to 2012. The average withdrawn trend deemed to be most representative for the Querétaro valley is marked in blue solid lines. Between 1970 and 1975 the average decline rate of these wells was less than 2 $\mathrm{m} / \mathrm{yr}$; after 1975 the slope increased to $3 \mathrm{~m} / \mathrm{yr}$. Some wells exhibit a different behavior: a significantly lower withdrawal (green dashed lines), a behavior similar to the average rate but presenting a slightly lower rate of depletion in the last measurements (yellow lines), and two wells with a drawdown higher than the average (gray dotted lines). Most of the wells other than the blue group are located in faulted zones.
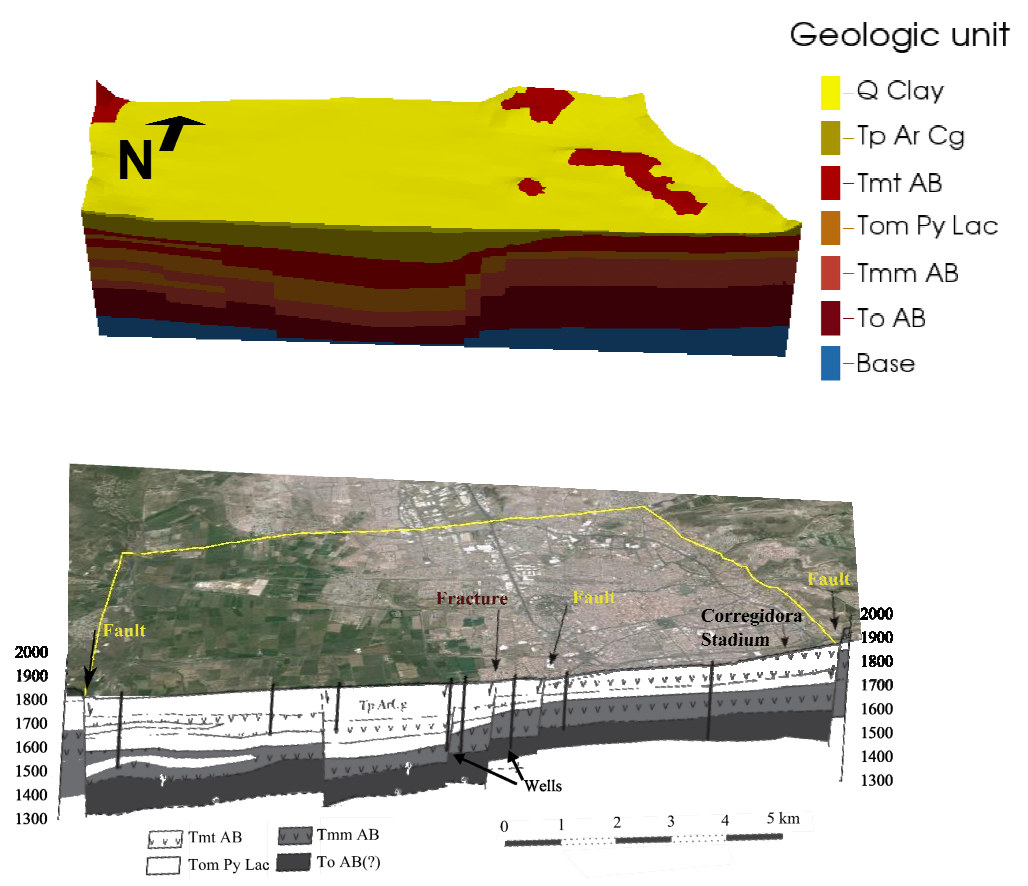

Figure 3. Comparison between the geological model used in the simulation and a geological section reconstructed by Carreon-Freyre et al. (2005b). 
Earth fissuring due to groundwater withdrawal have been reported in Querétaro City since 1986. The occurrence is strongly affecting the urban infrastructures (Trejo and Martinez 1991). Particularly fracturing has been associated in Querétaro with the differential subsidence caused by the variations in thicknesses of the compressible layers (Rojas et al., 2002).

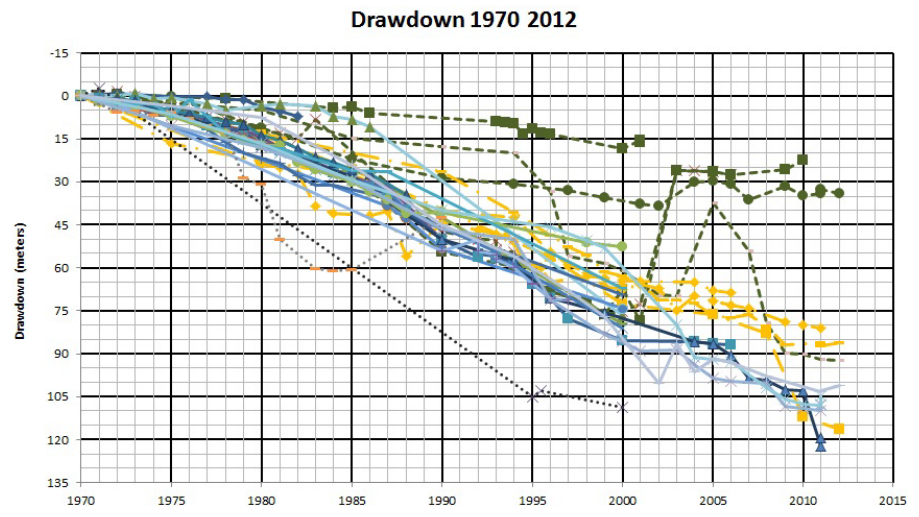

Figure 4. Historical drawdown from 1970 to 2012 in the Querétaro Vallev. Blue colors indicate the average trend.

\section{MODELLING SOIL DEFORMATION DUE TO GROUNDWATER PUMPING}

\subsection{Modelling Approach}

The deformation of a porous medium caused by fluid withdrawal is theoretically described by the threedimensional fully coupled poroelasticity model originally developed by Biot (1941). Typically, one-way coupling between the flow and the strain fields is assumed in the classical groundwater hydrology (e.g., Gambolati et al., 2000; Teatini et al., 2006), with the hydrodynamics of the pumped aquifer system first simulated by a 3-D groundwater flow model and the subsidence then computed with the aid of a 3-D poromechanical model with the pore pressure field specified as an external distributed source of strength within the porous medium.

For the sake of simplicity, the modelling approach is based on the assumption of a potential flow problem. Hence in the preliminary simulations that follow, the aquifer hydrodynamics is governed by the classical groundwater flow equation:

$$
\nabla(K \nabla h)=S_{s} \frac{\partial h}{\partial t}+q
$$

where $h$ is the hydraulic head, $t$ is time, $q$ the source/sink, and $S_{s}$ the specific elastic storage. Equation (1) is solved in space by linear finite elements (tetrahedra) and in time by a weighted finite difference scheme.

The incremental pressure $\mathrm{p}=\gamma_{w} \Delta h$, with $\gamma_{w}$ the specific weight of water, induced by water pumping is used in the geomechanical model to compute the medium displacements. The equilibrium equations for a mechanically isotropic elastic porous medium, in terms of incremental quantities, read (e.g., Verruijt, 1969):

$$
G \nabla^{2} u_{i}+(G+\lambda) \frac{\partial \varepsilon}{\partial i}=\frac{\partial p}{\partial i} \quad i=x, y, z
$$

where $u_{i}$ is the displacement component along the $i$-th coordinate direction, $\lambda$ and $G$ are the Lamè constant and the shear modulus of the porous medium, respectively, and $\varepsilon$ is the volume strain. The solution to equations (2) is obtained by finite elements using the same tetrahedral elements as the groundwater flow model.

The parameters $S_{S}$ and $G$ are linked through the following well-known relations:

$$
S_{S}=\gamma_{w}\left(c_{M}+\phi \beta\right) \quad ; \quad c_{M}=\frac{1}{\lambda+2 G}=\frac{(1+v)(1-2 v)}{E(1-v)} \quad ; \quad G=\frac{E}{2(1+v)}
$$

with $c_{M}$ the oedometric bulk compressibility, $\phi$ the medium porosity, $\beta$ the water volumetric compressibility, $E$ the Young modulus, and $v$ the Poisson ratio. The $c_{M}$ used to form $S_{s}$ or to compute $E$, $\lambda$, and $G$ is the same in both the flow and the geomechanical models.

The numerical approach used in this preliminary modelling study does not address explicitly failure generation and fissure mechanics due to groundwater pumping, e.g. by the use of appropriate formulation such as the Interface Elements (Ferronato et al., 2008). However, the 3-D geomechanical analysis allows for the computation of the complete stress field: 


$$
\sigma_{i}=2 G \frac{\partial u_{i}}{\partial i}+\lambda \varepsilon \quad ; \quad \tau_{i, j}=G\left(\frac{\partial u_{j}}{\partial k}+\frac{\partial u_{k}}{\partial j}\right) \quad i, j, k=x, y, z
$$

with the fissure generation and/or activation that are more likely to occur where the normal stress component $\sigma$ assumes negative (i.e., tensile) values or the tangential stress $\tau$ is relatively large with respect to compressive stress.

\subsection{Model set-up}

The simulated area (Figure 5) includes the oldest urban area and the surrounding farmland. This area is delimited by mayor geological structures (faults), but there are also faults inside the modeled domain. These latter cannot be observed at the ground surface but their geometry was defined with the aid of lithological well logs and geological and geophysical profiles.

The digital elevation model (DEM) represents the top surface of the domain. The thickness of the geologic units and discontinuities caused by faulting were obtained by analyzing 46 wells logs with varied depths, 11 gravimetric profiles (Pacheco et al., 2006), the geological profile showed in Figure 2 (Carreon-Freyre et al., $2005 \mathrm{~b}$ ), and geological profiles made for the purpose. The bottom boundary of the model, which is assumed to be a no flow surface, is represented by the top of the Base unit.

The model accounts for the seven main materials that compose the sedimentary-volcanic basin. A horizontal view of the mesh is shown in Figure 5. The mesh consists of 267,385 nodes and 1,520,244 tetrahedra, with each unit subdivided into 1 to $10 \mathrm{FE}$ layers.

The flow model, which is solved in term of piezometric drawdown from 1970, uses an initial equilibrated condition with the water elevation fixed to a constant reference value. This is surely an approximation of the actual condition but it is quite effective for the computation of the forcing term for the geomechanical simulations. Fixed Dirichlet conditions are prescribed along the lateral boundaries assuming a zero piezometric change over time.

The model is stressed by the water extraction from 123 wells (Figure 4) over a period of 31 years (11500 days), i.e. from 1970 to 2001. Pumping rates are known for 21 wells. The remaining 102 well rates were estimated on the basis of other available information. Standard Dirichlet conditions are assumed in the geomechanical model. The basement is assumed to be fixed, the horizontal displacements of the outer boundaries are precluded and the top surface is left free to move both vertically and horizontally. The 1970 setting is assumed as the reference equilibrated state.

\section{MODELING RESULTS}

The modeling results show a maximum drawdown of $160 \mathrm{~m}$ to the East of the "Las Campanas" hill with a flux boundary associated to the "5 de Febrero" fault (Figure 6a). Contrasting hydraulic gradients can be observed in both East and West sides of the fault. On the other hand, surface deformation is localized in the West side of the fault (dark zone in Figure 6b) with a maximum vertical displacement equal to 2 $\mathrm{m}$ corresponding to a deformation rate of 6.5

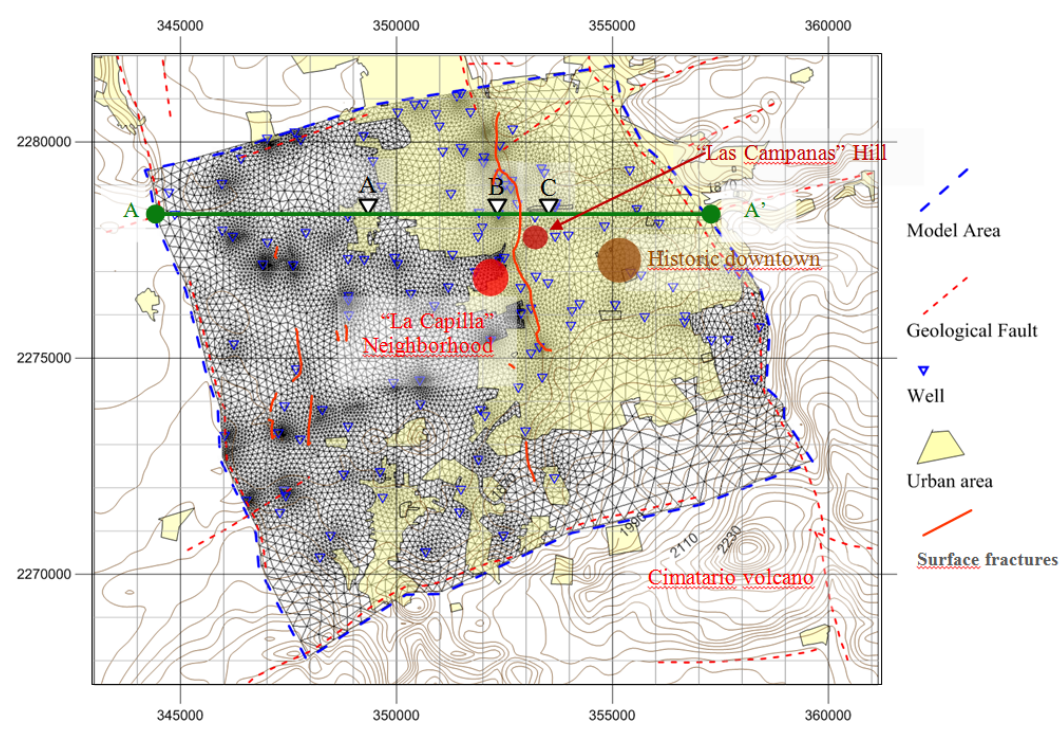

Figure 5. Horizontal projection of the 3D FE grid with the location of the main well fields used to withdraw water from the subsurface. The dashed red lines correspond to major normal faults delimiting the study area. The topographic elevation is represented by the brown curves. 

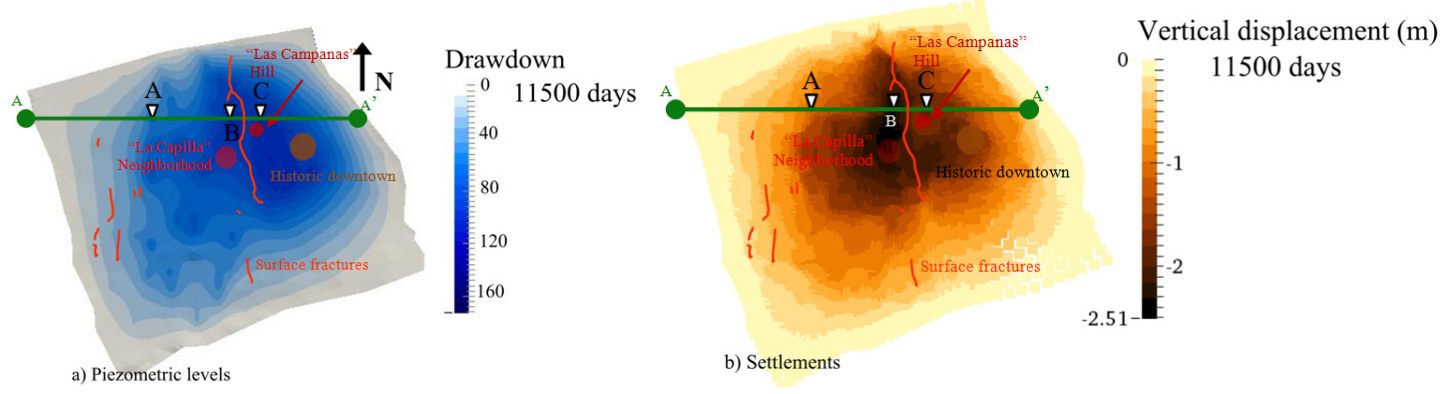

Figure 6. Simulated piezometric level and cumulative land subsidence between 1970 and 2001.

$\mathrm{cm} / \mathrm{yr}$. In the west side of the fault the deformation rate was less than $3 \mathrm{~cm} / \mathrm{yr}$.

These results provide evidence that land subsidence cannot be related to the piezometric change only. It appears that the variation of thickness and compressibility of the granular materials plays a major role. In the model section of Figure 7, the differences in subsurface structure and the relationship between the distribution of hydrostratigraphic units and water withdrawn are shown. On the ground surface (Figure 6) a higher drawdown within fractured volcanic rock units with a lower specific elastic storage and a lower deformability can be observed (C zone, nearby "Las Campanas" hill). At B zone, a thicker granular sequence and the " 5 de Febrero" fault may influence the hydraulic behavior (Figure 6). The higher drawdown occurs at shallower depths (approximately $150 \mathrm{~m}$ ) and is localized in the granular area with $100 \mathrm{~m}$ thickness. The A zone is located in an area with thicknesses similar to the other zones; the normal faulted bedrock (Figure 7) affect the piezometric variations versus depth. In this zone the surface deformation does not seem to reflect the deep structural variations but is mainly related to the surface drawdown.

Groundwater depletion and vertical deformation for the three studied zones of the section are provided in Table 1.

Table 1. Comparison between drawdown and surface settlement for the sites highlighted in Figures 6 and 7.

\begin{tabular}{|l|c|c|c|}
\cline { 2 - 4 } \multicolumn{1}{c|}{} & A Point & B Point & C Point \\
\hline $\begin{array}{l}\text { Water drawdown } \\
\text { at surface }(\mathrm{m})\end{array}$ & $\begin{array}{c}73.44 \\
(\mathrm{~min} .)\end{array}$ & 106.93 & $\begin{array}{l}122.06 \\
(\max .)\end{array}$ \\
\hline Surface settlement (m) & 1.11 (min.) & 2.25 (max.) & 1.78 \\
\hline
\end{tabular}

\section{DISCUSSION AND CONCLUSION}

This work presents a modeling investigation on the relationship between the variability of the geomechanical properties and the differential deformation of the Querétaro volcano-sedimentary sequences. This issue has not been addressed in the literature. Since the early $80 \mathrm{~s}$, the influence of bedrock topography on the deformation and fracture generation of overlying granular materials has been reported (Jaechens and Holzer, 1982) and many further studies were focused on this aspect. The modeling results presented here show that thickness variations of fractured volcanic and granular units directly affect the pressure changes in the deep layers and the deformation at the surface. Model outputs suggest that the larger land subsidence is not necessarily associated with the major withdrawn, as mentioned by Bell (2002). Model sections allow for a better understanding of groundwater depletion in zones B and $\mathrm{C}$, which could not be achieved only with local piezometric measurements. The model can be further improved using the actual initial piezometric surface (instead of a flat one) and more realistic flow boundary

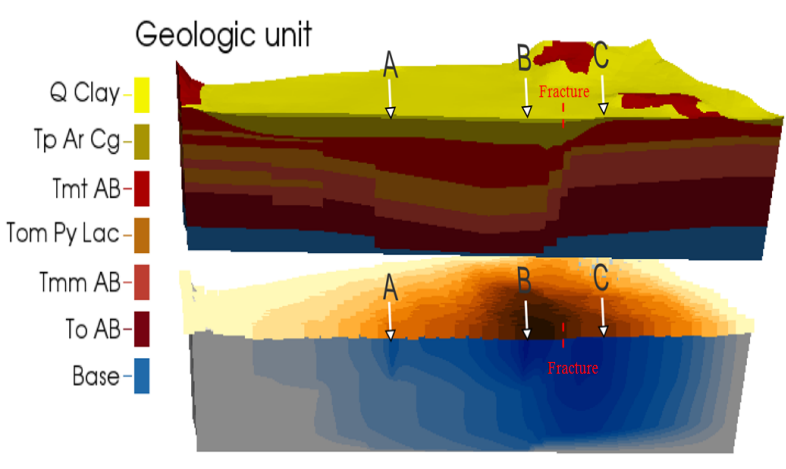

Figure 7. Vertical section of the model showing the subsoil structure and the variations of groundwater pressure in depth. Maximum depth is approximately $500 \mathrm{~m}$. 
Ochoa-González et al., Modeling land deformation due to groundwater pumping at Querétaro, Mexico

\section{REFERENCES}

Alaniz-Alvarez S.A., Nieto-Samaniego A.F., Reyes-Zaragoza M.A. (2001) Estratigrafía y deformación extensional en la región San Miguel de Allende-Querétaro, México (Stratigraphy and extensional deformation in the San Miguel de Allende-Queretaro region, Mexico). Revista Mexicana de Ciencias Geologicas 18(2):129-148.

Bell, J.W., Amelung, F., Ramelli, A.R., Blewitt, G. (2002). Land Subsidence in Las Vegas, Nevada, 19352000: New Geodetic Data Show Evolution, Revised Spatial Patterns, and Reduced Rates. Environmental \& Engineering Geoscience, 8 (3), 155-174.

Biot, C. (1941). General theory of three-dimensional consolidation. Journal of Applied Physics, 12(2), 155164.

Carreón-Freyre, D., Cerca Martínez, M., and Hernández Marín, M. (2005a). Propagation of fracturing related to land subsidence in the Valley of Querétaro, Mexico. In: Proc. 7th International Symposium on Land Subsidence (SISOLS 2005, Shanghai, China), vol. 1, pp. 155-164. ISBN 7-5323-8209-5.

Carreón-Freyre, D., Cerca, M., Luna-González, L., and Gámez-González, F. (2005b). Influencia de la estratigrafía y estructura geológica en el flujo de agua subterránea del Valle de Querétaro. Revista Mexicana de Ciencias Geológicas, 22 (1), 1-18.

Carreón-Freyre, D. (2010). Land subsidence processes and associated ground fracturing in Central Mexico. In: Land Subsidence, Associated Hazards and the Role of Natural Resources Development (Proceedings of EISOLS 2010), edited by D. Carreón-Freyre et al., pp. 149-157, Red Book Series Publication 339, IAHS Press, CEH Wallingford. UK. ISBN 978-1-907161-12-4.

INEGI (2011). Censo Nacional de Poblacion, 2010, Mexico. Instituto Nacional de Estadistica, Geografia e Informatica.

Ferronato, M., Gambolati, G., Janna, C., and Teatini, P. (2008). Numerical modelling of regional faults in land subsidence prediction above gas/oil reservoirs. International Journal for Numerical and Analytical Methods in Geomechanics, 32, 633-657.

Gambolati, G., Teatini, P., Bau', D., and Ferronato, M. (2000). The importance of poro-elastic coupling in dynamically active aquifers of the Po river basin, Italy. Water Resources Research, 36(9), 2443-2459.

Jachens, R.C. and Holzer, T.L. (1982). Differential compaction mechanism for earth fissures near Casa Grande, Arizona. Geological Society of America Bulletin, 93, 998-1012.

Karmalkar, A.V., Bradley, R.S., and Diaz, H. F. (2011). Climate change in Central America and Mexico: regional climate model validation and climate change projections. Climate Dynamics, 37(3-4), 605-629.

López-Quiroz, P., Doin, M. P., Tupin, F., Briole, P., and Nicolas, J. M. (2009). Time series analysis of Mexico City subsidence constrained by radar interferometry. Journal of Applied Geophysics, 69(1), 1-15.

Pacheco, J., Arzate , J., Rojas, E., Arroyo, M., Yutsis , V., and Ochoa, G. (2006). Delimitation of ground failure zones due to land subsidence using gravity data and finite element modeling in the Querétaro valley, México. Engineering Geology, 84, 143-160.

Rojas, E., Arzate , J., and Arroyo, M. (2002). A method to predict the group fissuring and faulting caused by regional groundwater decline. Engineering Geology, 65, 245-260.

Teatini, P., Ferronato, M., Gambolati, G., and Gonella, M. (2006). Groundwater pumping and land subsidence in the Emilia- Romagna coastland, Italy: Modeling the past occurrence and the future trend. Water Resource Research, 42, W01406, doi:10.1029/2005WR004242.

Trejo-Moedano, A., Martínez-Baini, A. (1991). Agrietamiento de suelos zona de Querétaro. Agrietamiento de Suelos, Sociedad Mexicana de Mecánica de Suelos, A. C. 67-73.

Verruijt, A. (1969). Elastic storage of aquifers. In Flow Through Porous Media, edited by R. De Wiest, pp. 331-376, Elsevier, New York.

Xu, S., Nieto-Samaniego, A.F., Alaniz Alvarez, S.A., Cerca-Martinez, L.M. (2011). Structural analysis of a relay ramp in the Queretaro Graben, central Mexico: Implications for relay ramp development. Revista Mexicana de Ciencias Geologicas, 28(2), 275-289. 